\title{
The effect of silica nanoparticles on the morphology, mechanical properties and thermal degradation kinetics of polycarbonate
}

\author{
T.E. Motaung ${ }^{a}$, M.L. Saladino ${ }^{b, *}$, A.S. Luyt ${ }^{a}$, D.F. Chillura Martino ${ }^{b}$ \\ a Department of Chemistry, University of the Free State (Qwaqwa Campus), Private Bag X13, Phuthaditjhaba 9866, South Africa \\ ${ }^{\mathrm{b}}$ Department of Chemistry "S.Cannizzaro", University of Palermo, Parco d'Orleans II-Viale delle Scienze pad.17, Palermo I-90128, Italy
}

\section{A R T I C L E I N F O}

\section{Article history:}

Received 10 July 2012

Received in revised form 17 August 2012

Accepted 22 August 2012

Available online 8 September 2012

\section{Keywords:}

A. Polymer-matrix composites (PMCs)

A. Nano-composites

B. Mechanical properties

B. Thermal properties

\begin{abstract}
A B S T R A C T
Polycarbonate/silica nanocomposites with different silica quantities were prepared by a melt compounding method. The effect of silica amount, in the range 1-5 wt.\%, on the morphology, mechanical properties and thermal degradation kinetics of polycarbonate (PC) was investigated. Clusters of silica nanoparticles were well dispersed in the polycarbonate whose structure remained amorphous. NMR results showed intermolecular interactions involving the carbonyl groups of different polymeric chains which did not affect the intramolecular rotational motions. The presence of the lowest silica content showed a decrease in the storage and loss moduli below the glass transition temperature, probably due to a plasticization effect. However, an increase in the amount of silica increased the moduli. The presence of silica in PC slightly increased the thermal stability, except for the highest silica content which showed a decrease. The activation energies of thermal degradation for the nanocomposites depended on the amount of silica and on the degree of conversion.
\end{abstract}

(c) 2012 Elsevier Ltd. All rights reserved.

\section{Introduction}

Polycarbonate (PC) nanocomposites are a very attractive material for a range of industrial applications due to the unique properties that can be observed when compared to conventional composites. The incorporation of small amounts of metal oxide nanoparticles into the polymer matrices was found to remarkably improve dimensional stability, and the mechanical, thermal, optical, electrical, and gas barrier properties, as well as to decrease the flammability [1-6]. PC-silica nanocomposites, prepared by various methods, attracted the attention of many institutions due to their improved transparency and mechanical properties $[7,8]$.

The preparation of the nanocomposites by a simple one-step injection molding process showed the presence of primary silica nanopowders, together with some small nanocluster aggregates, well dispersed in the polymer matrix $[7,8]$. The dispersion was related to a possible chemical bonding between the organic and inorganic phases. The glass transition temperature $\left(T_{\mathrm{g}}\right)$ of the PC was found to increase with the addition of $5 \mathrm{wt} . \%$ silica nanopowder. The results also showed that the incorporation of silica nanopowders enhanced the thermal stability of the polymer where the chain segment motion was restricted by the interfacial-particle interactions between the surface functionalized-silica nanopowders and the polymer molecules [7].

\footnotetext{
* Corresponding author.

E-mail address: marialuisa.saladino@unipa.it (M.L. Saladino).
}

Other studies indicated that the increase in silica content in a PC matrix prepared by sol-gel led to a decrease in both the glass transition temperature and the thermal stability. The observation was related to the presence of a steric hindrance on the formation of a silica network $[9,10]$. Well dispersed aggregates were observed and the size of the $\mathrm{SiO}_{2}$ domains increased with increasing amount of TEOS in sol-gel prepared nanocomposites $[9,10]$.

The PC-silica nanocomposites at lower loading of modified silica prepared by melt mixing showed an enhancement in thermal stability, an increase in storage modulus, scratch resistance, and hardness compared to pristine PC. This was related to the reduced particle-particle interactions dominated by hydrogen bonding ensued from the hydroxide groups on the silica surface and the carbonyl groups in the PC $[8,11]$.

A similar reason was given for the increased storage modulus of the nanocomposites prepared by solution mixing [12]. However, the storage modulus values showed no significant difference between the samples containing unmodified and modified silica. This observation was also related to hydrogen bonding. The volumetric strain was also investigated at the cross-section where the necking dominates. The results showed that the filler brought significant differences in the onset and propagation of necking and those where related to a disrupted molecular structure of the polymer by the filler.

The aim of this work was to investigate the thermal, mechanical and degradation behavior of PC-silica nanocomposites as function of silica loading. $\mathrm{PC}-\mathrm{SiO}_{2}$ nanocomposites were prepared through a 
melt compounding method by using chemically modified $\mathrm{SiO}_{2}$ nanoparticles. Both nanoparticles and composites were characterized using transmission electron microscopy (TEM), X-ray diffractometry (XRD), dynamic mechanical analysis (DMA), thermogravimetric analyses (TGA), and ${ }^{13} \mathrm{C}$ cross-polarization magicangle spinning nuclear magnetic resonance $\left({ }^{13} \mathrm{C}\left\{{ }^{1} \mathrm{H}\right\}\right.$ CP-MAS NMR).

\section{Experimental}

\subsection{Materials}

AEROSIL $^{\circledR}$ R972 (R972, Degussa, Germany) is a hydrophobic silica having chemically surface bonded methyl groups, based on a hydrophilic fumed silica with a specific surface area of $130 \mathrm{~m}^{2} \mathrm{~g}^{-1}$ and an average primary particle size of $16 \mathrm{~nm}$. The silica was dried at $120^{\circ} \mathrm{C}$ under static vacuum for a minimum of $16 \mathrm{~h}$ before further use. Commercial grade bisphenol-A polycarbonate (PC, Makrolon ${ }^{\circledR} 2407$ produced by Bayer Material Science, Germany and having a melt flow rate at $300{ }^{\circ} \mathrm{C} / 1.2 \mathrm{~kg}$ of $20 \mathrm{~g} /$ $10 \mathrm{~min}$ ) was used in pellet form. The polymer was dried at $120^{\circ} \mathrm{C}$ overnight under static vacuum before processing.

\subsection{Composites preparation}

PC was thoroughly mixed with 1,2 and 5 wt.\% silica for 10 min at $240{ }^{\circ} \mathrm{C}$ and $30 \mathrm{rpm}$ in the $50 \mathrm{~mL}$ internal mixer of a Brabender Plastograph from Duisburg, Germany. The mixed samples were melt-pressed into $1 \mathrm{~mm}$ thick sheets at $200{ }^{\circ} \mathrm{C}$ for $5 \mathrm{~min}$.

\subsection{Analysis methods}

TEM micrographs were acquired using a JEM-2100 (JEOL, Japan) electron microscope operating at $200 \mathrm{kV}$ accelerating voltage. The obtained nanocomposites were cut into slices (thickness about $100 \mathrm{~nm}$ ) using a Leica EM UC6 ultra-microtome. Slices were put and analyzed in a $3 \mathrm{~mm}$ Cu grid "lacey carbon".

$X R D$ patterns were recorded in the $2-70^{\circ} 2 \theta$ range at steps of $0.05^{\circ}$ and a counting time of $5 \mathrm{~s} /$ step on a Philips PW 1050 diffractometer, equipped with a $\mathrm{Cu}$ tube and a scintillation detector beam.

The dynamic mechanical properties of the composites were investigated from 40 to $180^{\circ} \mathrm{C}$ in the bending mode at a heating rate of $5{ }^{\circ} \mathrm{C} \mathrm{min}-1$ and a frequency of $1 \mathrm{~Hz}$ using a Perkin Elmer Diamond DMA from Waltham, Massachusetts, U.S.A. The glass transition temperatures were determined from the peak maxima in the tan $\delta$ curves.

Thermogravimetric analysis (TGA) was performed in a Perkin Elmer TGA7 from Waltham, Massachusetts, U.S.A under flowing nitrogen at a constant flow rate of $20 \mathrm{~mL} \mathrm{~min}^{-1}$. Samples (5$10 \mathrm{mg}$ ) were heated from 25 to $600{ }^{\circ} \mathrm{C}$ at different heating rates. The degradation kinetic analysis was performed using the FlynnWall-Ozawa (FWO) and Kissinger-Akahira-Sunose (KAS) methods, described elsewhere [13]. The\% mass loss, or mass loss fraction, was used as the degree of conversion in our calculations.

The TGA-FTIR analyses were performed using a Perkin Elmer STA6000 simultaneous thermal analyzer from Waltham, Massachusetts, USA, under flowing nitrogen at a constant flow rate of $20 \mathrm{~mL} \mathrm{~min}^{-1}$. Samples (20-25 mg) were heated from 30 to $600{ }^{\circ} \mathrm{C}$ at $10^{\circ} \mathrm{C} \mathrm{min}^{-1}$ and held for $4 \mathrm{~min}$ at $600{ }^{\circ} \mathrm{C}$. The furnace was linked to a FTIR (Perkin Elmer Spectrum 100, Massachusetts, USA.) with a gas transfer line. The volatiles were scanned over a $400-4000 \mathrm{~cm}^{-1}$ wavenumber range at a resolution of $4 \mathrm{~cm}^{-1}$. The FTIR spectra were recorded in the transmittance mode at different temperatures during the thermal degradation process.
${ }^{13} \mathrm{C}\left\{{ }^{1} H\right\} C P-M A S$ NMR spectra were obtained at room temperature through a Bruker Avance II $400 \mathrm{MHz}$ (9.4 T) spectrometer operating at $100.63 \mathrm{MHz}$ for the ${ }^{13} \mathrm{C}$ nucleus with a MAS rate of $8 \mathrm{kHz}, 500$ scans, a contact time of $1.5 \mathrm{~ms}$ and a repetition delay of $2 \mathrm{~s}$. The optimization of the Hartmann-Hahn condition [14] was obtained using an adamantine sample. Each sample was placed in a $4 \mathrm{~mm}$ zirconia rotor with KEL-F caps using silica as filler to avoid inhomogeneities inside the rotor. The proton spin-lattice relaxation time in the rotating frame $T_{1 \rho}(\mathrm{H})$ was indirectly determined, with the variable spin lock (VSL) pulse sequence, by the carbon nucleus observation using a $90^{\circ}-\tau$-spin-lock pulse sequence prior to cross-polarization [15]. The data acquisition was performed by ${ }^{1} \mathrm{H}$ decoupling with a delay time, $\tau$, ranging from 0.1 to $7.5 \mathrm{~ms}$ and a contact time of $1.5 \mathrm{~ms}$. The proton spin-lattice relaxation time in the laboratory frame $T_{1}(\mathrm{H})$ was determined, using the saturation recovery pulse sequence [16], by a carbon nucleus observation using a $90^{\circ}-\tau-90^{\circ}$ pulse sequence prior to cross polarization with a delay time $\tau$ ranging from 0.01 to $3 \mathrm{~s}$. The ${ }^{13} \mathrm{C}$ spin-lattice relaxation time in the rotating frame $T_{1}(\mathrm{C})$ was determined, with the variable spin lock (VSL) pulse sequence, applying the spin-lock pulse after the cross-polarization on the carbon channel [15]. The data acquisition was performed by ${ }^{1} \mathrm{H}$ decoupling with a spin lock pulse length, $\tau$, ranging from 0.4 to $30 \mathrm{~ms}$ and a contact time of $1.5 \mathrm{~ms}$. The cross polarization time $T_{\mathrm{CH}}$ values for all the carbon signals of PC were obtained through variable contact time (VCT) experiments [17]. The contact times used in the VCT experiments were $0.05,0.1,0.2,0.3,0.4,0.5,0.6,0.8,1.0,1.2,1.5$, $2.0,2.5,3.0,3.5,4.0,4.5,5.0,6.0$ and $7.0 \mathrm{~ms}$.

\section{Results and discussion}

TEM micrographs of the $\mathrm{SiO}_{2}$ powder were reported in a previous paper [13]. Silica powder shows aggregates (sizes between 1 and $3 \mu \mathrm{m}$ ) constituted of a large number of nanoparticles of $\sim 20 \mathrm{~nm}$. The TEM micrographs of the PC-silica nanocomposite having 5 wt.\% of $\mathrm{SiO}_{2}$ are shown in Fig. 1. Agglomerated silica particles, similar in size and shape to those observed in the powder sample, are observed. Each cluster, with dimensions between 50 and $300 \mathrm{~nm}$, and with a number of small nanoparticles, is well dispersed in the polymeric matrix.

The XRD patterns of the $\mathrm{SiO}_{2}$ powder and the $\mathrm{PC}-\mathrm{SiO}_{2}$ composites are reported in Fig. 2. The diffraction pattern of the silica powder shows a broad band around $2 \theta=21.2$, typical of an amorphous material. The diffraction pattern of pure PC does not contain any crystalline reflection indicating that polycarbonate is also amorphous. Similar diffraction patterns were obtained for the PC-silica nanocomposites indicating that neither the orientation of the PC chains nor the amorphous structure of the silica was influenced by the presence of the filler.

The storage modulus, loss modulus and $\tan \delta$ of the pure PC and the PC-silica composites having 1,2 and $5 \mathrm{wt} . \%$ of $\mathrm{SiO}_{2}$ are reported in Fig. 3. Below the glass transition temperature the storage modulus of the $1 \%$ silica containing nanocomposite is lower than that of PC, probably because of a plasticizing effect by the small amount of well dispersed silica nanoparticles on the PC matrix. Further increase in silica content increased the storage modulus over the whole temperature range. It seems as if effective immobilization of the polymer chains only takes place at higher silica contents. The loss modulus followed the same pattern as the storage modulus. The glass transition temperatures for all composites are higher than that of pure PC, indicating that effective immobilization already starts when $1 \%$ nanoparticles are introduced into the polymer.

The TGA curves of the pure PC and of the PC-silica composites are reported in Fig. 4. 

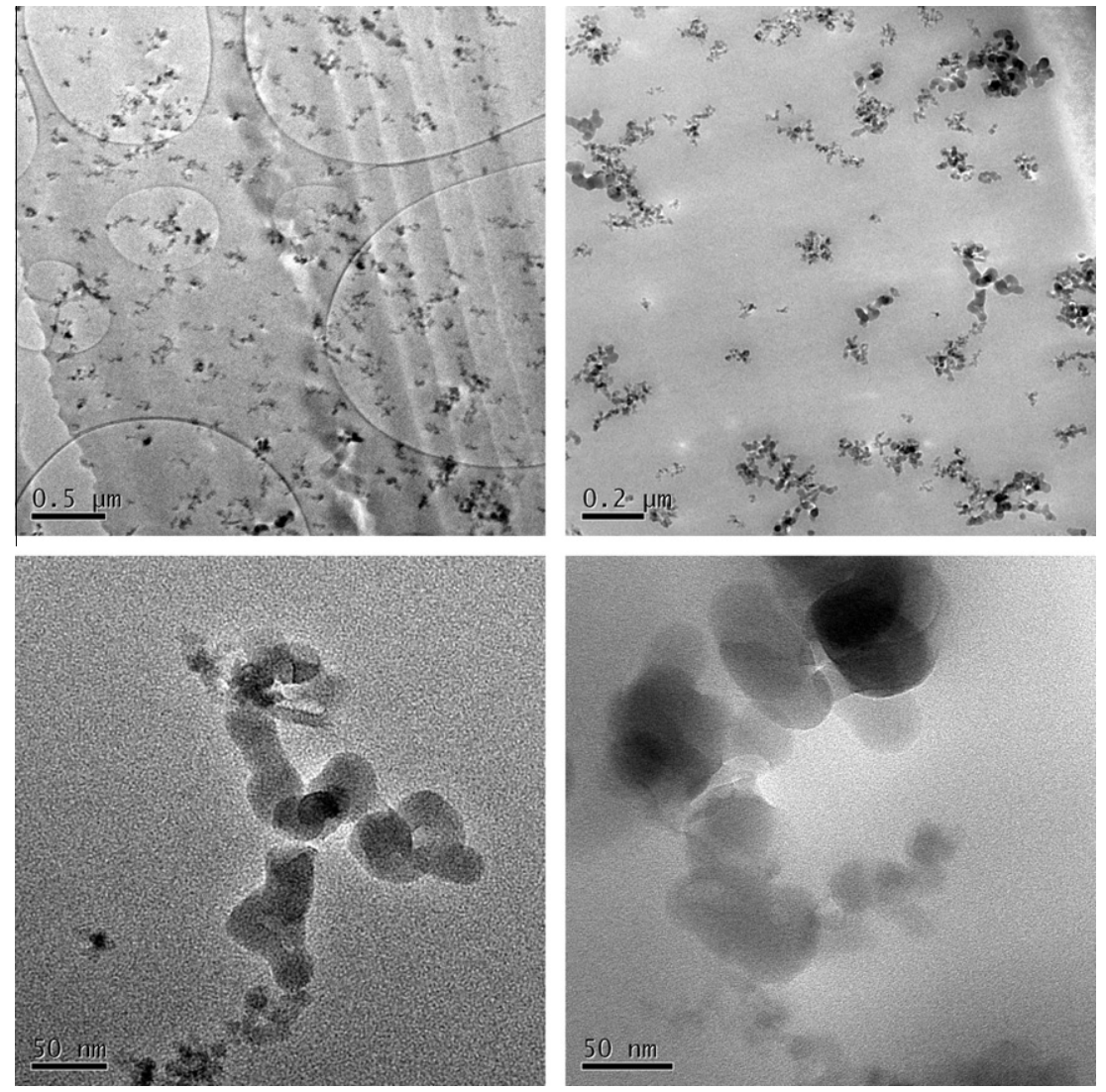

Fig. 1. TEM micrographs of silica-PC composite having 5 wt.\% of $\mathrm{SiO}_{2}$.

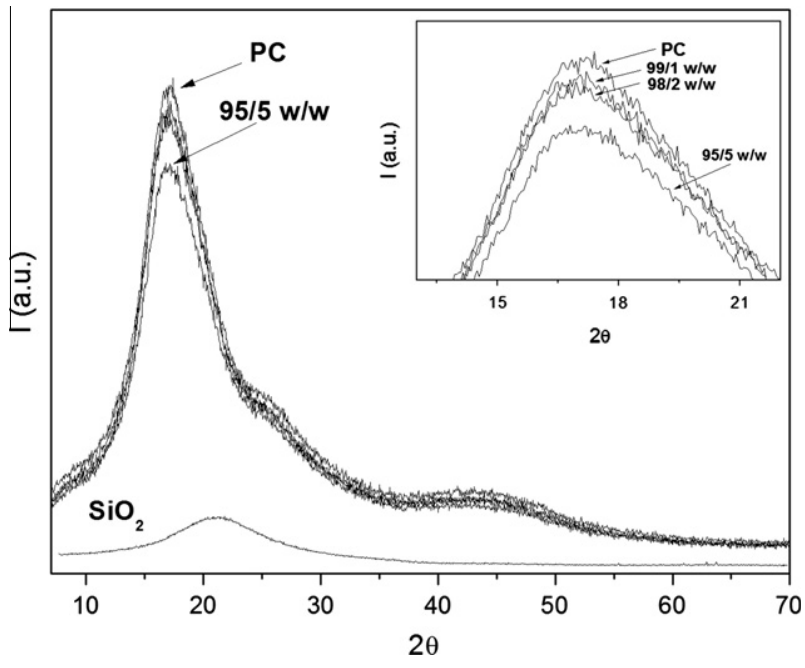

Fig. 2. XRD patterns of silica powder, pure PC and the silica-PC nanocomposites.

All the samples show single-step degradation, which very slightly moves to higher temperatures with increasing amount of silica, except for the $5 \%$ silica containing sample, which showed lower thermal stability than PC. The increase in thermal stability is not significant enough to be discussed in detail, but it could be attributed to interactions between the organically modified silica and the polymer, while the decrease for the $5 \%$ silica containing sample is probably due to a catalytic effect of the silica particles on the PC degradation, as discussed below.
From the TGA curves of PC and PC-silica (2 and 5 wt.\%) at heating rates of 3,5, 7 and $9{ }^{\circ} \mathrm{C} \mathrm{min}{ }^{-1}$ the isoconversional graphs of $\ln \beta$ versus $1 / T$ and of $\ln \left(\beta / T^{2}\right)$ versus $1 / T$ were plotted, according to FWO and KAS methods, respectively [13]. The activation energy values were calculated from the slopes of the isoconversional plots. Both isoconversional methods give similar values of the activation energies within experimental uncertainty. In Fig. 5 the relationship between the activation energy and the degree of conversion is reported. The activation energy values for the pure PC and its $2 \mathrm{wt} . \%$ silica nanocomposite increase with the degree of conversion, but those for the $5 \mathrm{wt}$ \% silica nanocomposite initially increase but level off around $40 \%$ mass loss, and are lower than those of the pure polymer. The $2 \mathrm{wt} . \%$ silica nanocomposite shows the highest activation energy values up to $40 \%$ mass loss, while at higher degrees of conversion its activation energy values are between those of the pure polymer and the $5 \mathrm{wt}$.\% silica nanocomposite.

The increase in activation energy with an increase in degree of conversion was also observed by us when investigating PMMA$\mathrm{SiO}_{2} / \mathrm{TiO}_{2} \cdot \mathrm{ZrO}_{2}$ nanocomposites $[13,18,19]$ and by several other authors [20-22]. It was generally explained as changes in the degradation mechanism with increasing degree of conversion. Dong et al. [23] investigated PC-MgO nanocomposites, and they attributed the increase in activation energy of degradation with increasing degree of conversion to the stable carbonaceous char which protects the polymer from further degradation. They also observed that an increase in MgO content shifted the TGA curves to lower temperatures, and that the initial activation energy values for the PC-MgO nanocomposites were lower than those of pristine PC. They attributed these observations to a catalytic effect the $\mathrm{MgO}$ nanoparticles have during the initial stages of PC degradation, which was also observed during the investigation of other, but similar, systems [19]. Their activation energy values correspond 

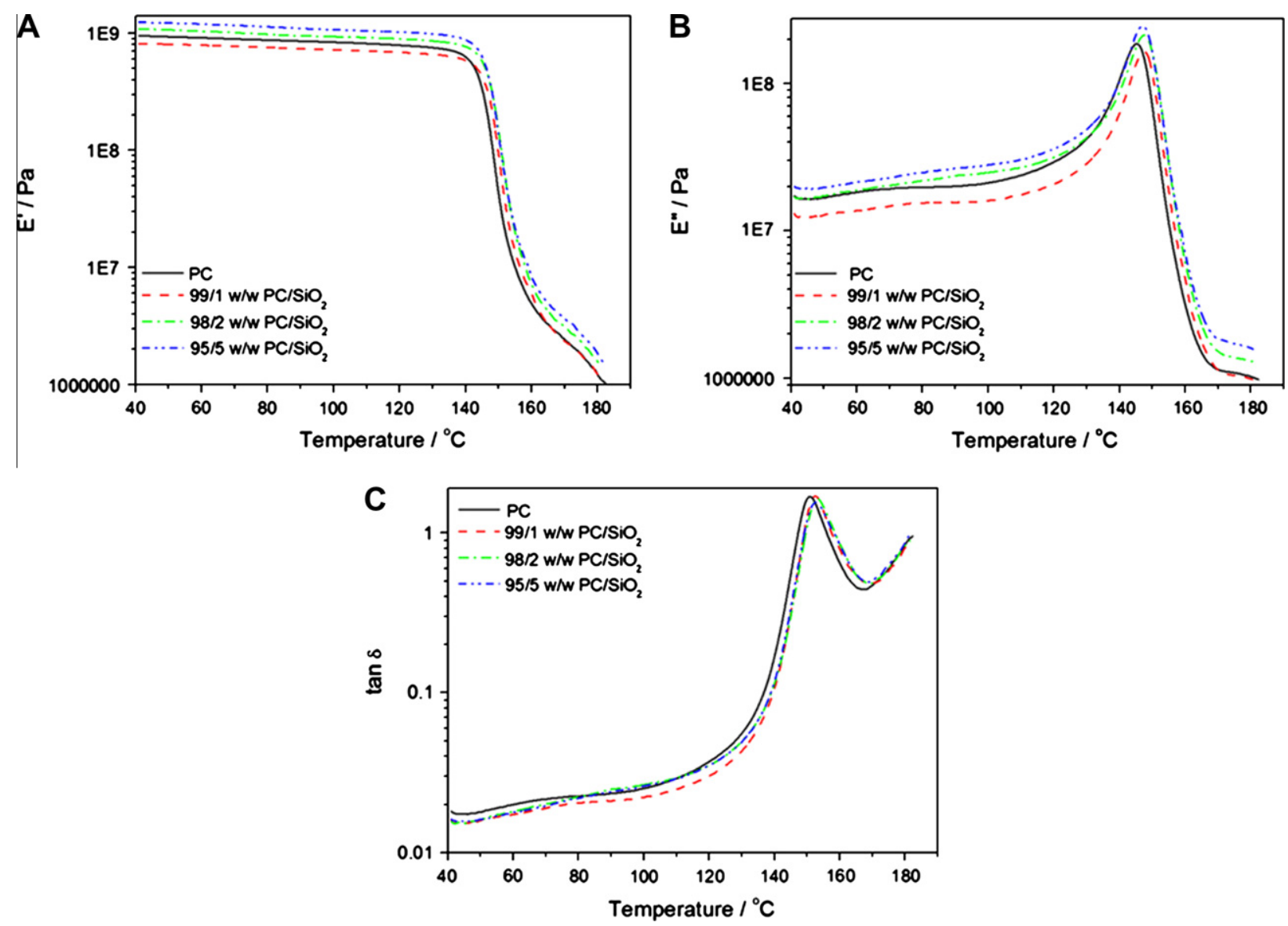

Fig. 3. (A) Storage modulus, (B) loss modulus and (C) $\tan \delta$ curves of PC and PC/silica nanocomposites.

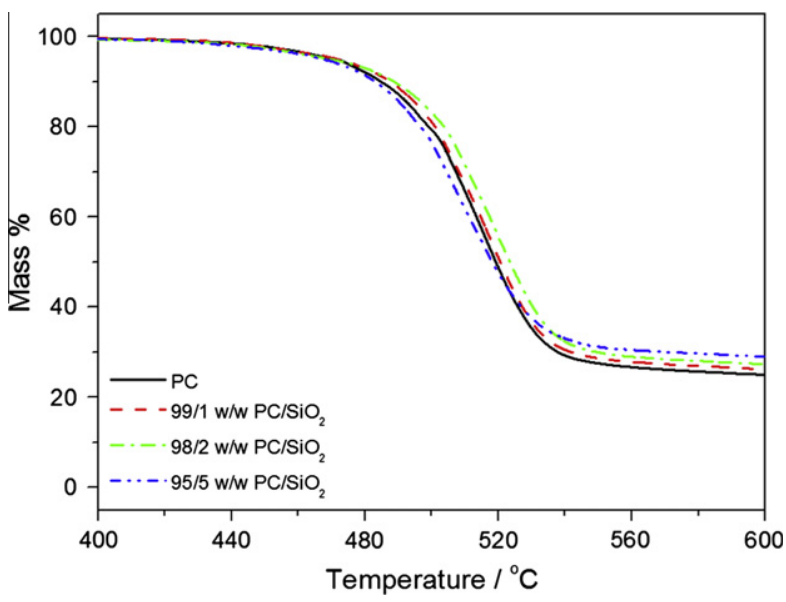

Fig. 4. TGA curves of $\mathrm{PC}$ and the $\mathrm{PC} /$ silica nanocomposites.

very well with the values we reported in Fig. 5. We observed a similar change in activation energy with increasing degree of conversion for PC-silica nanocomposites [13]. Like MgO, low quantities of silica seem to have a catalytic effect during the initial stages of the degradation. In our case, however, the protecting effect of the carbonaceous char is more dominant during the later stages of degradation. If one looks at the results of the $5 \%$ silica containing PC (Fig. 5), it is clear that the catalytic effect is more dominant and the activation energies for this nanocomposite are clearly lower

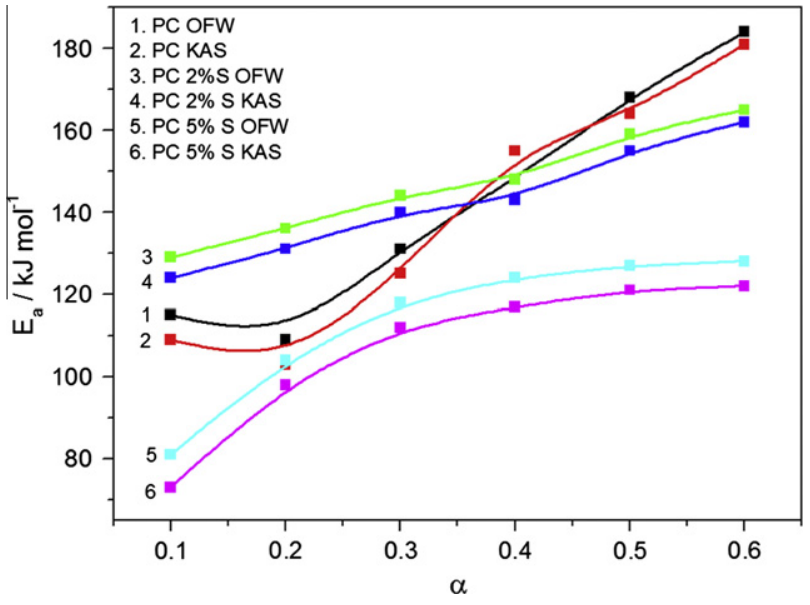

Fig. 5. $E_{a}$ values obtained by the OFW and KAS degradation kinetics methods.

than those of the pristine PC and the $2 \%$ silica containing PC over the whole degree of conversion range. The values for the $5 \%$ silica containing PC also approach a constant value at higher degrees of conversion, which shows that the protecting effect of the carbonaceous char is less dominant in this case, despite the fact that the char content is the same than those of PC and PC-silica (2\%) according to the TGA curves in Fig. 4.

TGA-FTIR analyses were done to establish the nature of the degradation product(s) of PC and the PC-silica nanocomposites. 

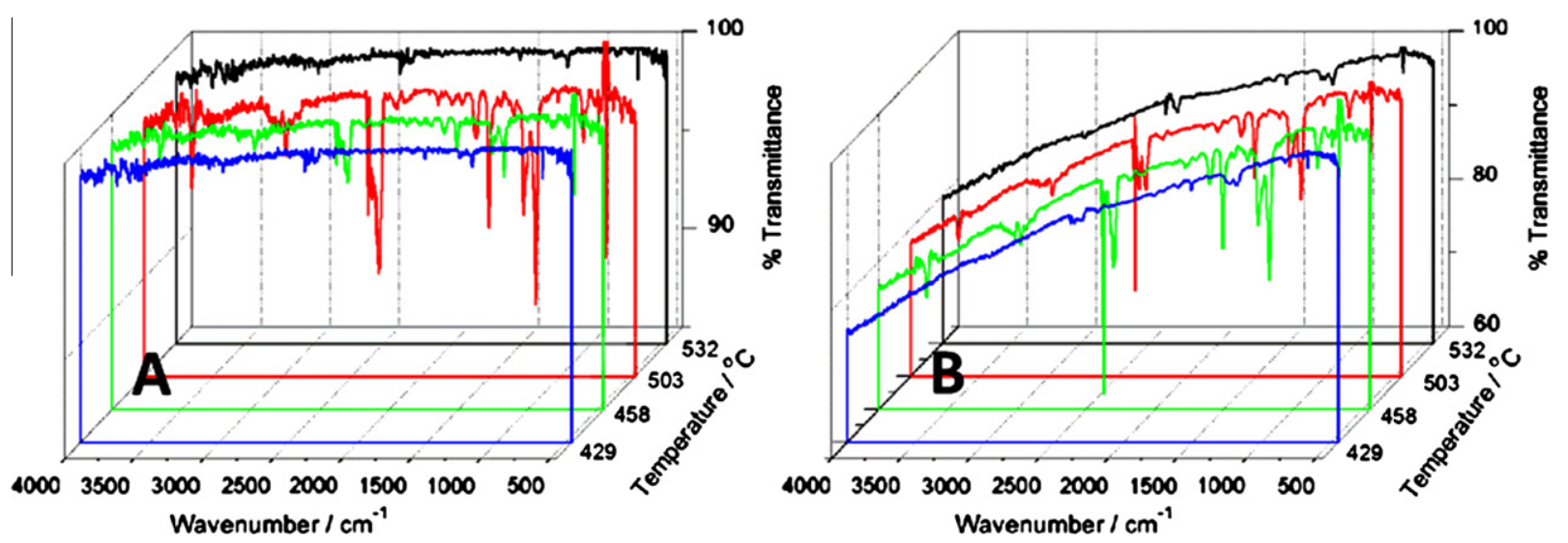

Fig. 6. FTIR curves at different temperatures during the thermal degradation of (A) PC in a TGA; (B) PC with 5 wt.\% silica in a TGA.

The FTIR spectra of the degradation products of pure PC at different temperatures during the degradation process are shown in Fig. 6A. All the spectra almost perfectly match the known spectrum of the thermal decomposition of bisphenol-A polycarbonate in which $\mathrm{CO}_{2}$, phenol and bisphenol $\mathrm{A}$ are the main volatile products. The observed peaks at 3658, 2974 and $1182 \mathrm{~cm}^{-1}$ are assigned to free alcohols (aliphatic substituted phenol), to $\mathrm{C}-\mathrm{H}$ stretching vibrations, and to the carbon hydroxyl stretching band. The peaks at 1606,1509 and $1257 \mathrm{~cm}^{-1}$ are assigned to the ring stretching, to skeletal vibration of phenyl compounds, and to the aromatic ether stretch. In addition, the peak observed in the range 2388$2119 \mathrm{~cm}^{-1}$ and at $833 \mathrm{~cm}^{-1}$ are due to the symmetric stretching and the bending modes of $\mathrm{CO}_{2}$, respectively. No new peaks or peak shifts were observed for the nanocomposite samples, the spectra of which are reported in Fig. $6 \mathrm{~B}$. The peaks at $458^{\circ} \mathrm{C}$ for the PC nanocomposite are more intense than those of the PC. The intensities of the peaks for PC seem to reach a maximum between 458 and $503{ }^{\circ} \mathrm{C}$, while those of the nanocomposite reach a maximum at $458^{\circ} \mathrm{C}$, which is in line with the lower activation energies of degradation observed for the nanocomposites.

${ }^{13} \mathrm{C}\left\{{ }^{1} \mathrm{H}\right\} \mathrm{CP}-\mathrm{MAS}$ NMR measurements were performed in order to understand the possible changes caused by the filler in the polymer and to attempt a correlation between the mechanical proper-

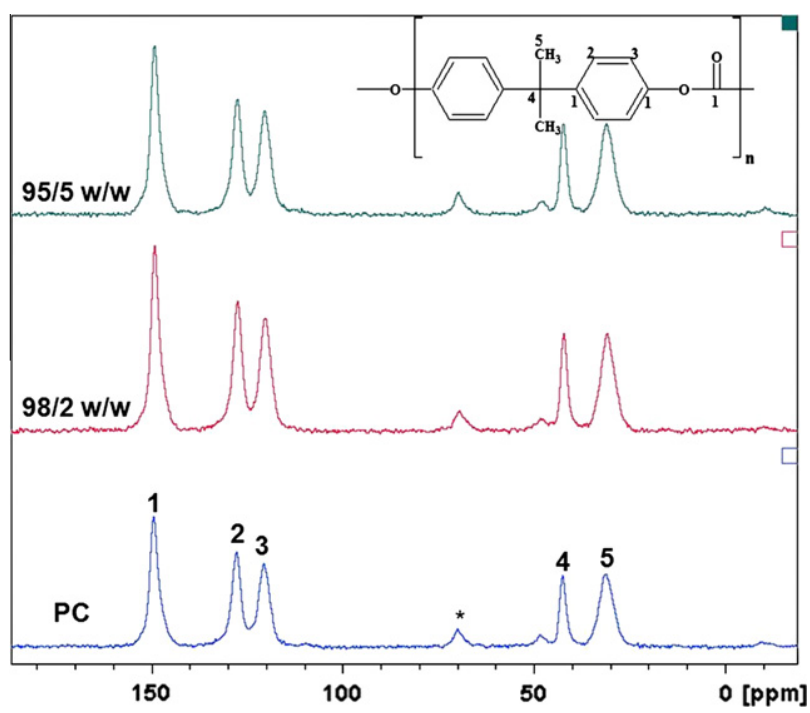

Fig. 7. ${ }^{13} \mathrm{C}\left\{{ }^{1} \mathrm{H}\right\}$ CP-MAS NMR spectra of PC and of and silica-PC nanocomposites. Numbers on the peaks identify the carbon atoms. The * symbol indicates spinning sidebands. ties, the kinetics of degradation and the molecular structure of the polymer. The ${ }^{13} \mathrm{C}\left\{{ }^{1} \mathrm{H}\right\} \mathrm{CP}-\mathrm{MAS}$ NMR spectra of the $\mathrm{PC}-\mathrm{SiO}_{2} \mathrm{com}-$ posites having 2 and $5 \%$ of silica are reported in Fig. 7. Five peaks are present in the spectra: peak 1 at $149 \mathrm{ppm}$ is related to the quaternary carbons of the aromatic rings and to the carbonyl carbon, peak 2 at $127 \mathrm{ppm}$ is related to the aromatic carbon in meta to the oxygen, peak 3 at $120 \mathrm{ppm}$ is related to the aromatic carbon in ortho to the oxygen, peak 4 at $42 \mathrm{ppm}$ is related to the quaternary carbon bonded to the methyl groups and peak 5 at $31 \mathrm{ppm}$ is related to the methyl carbons, according to literature [24]. No modification in the chemical shift and in the band shape is observed in the PC-silica nanocomposites spectra indicating that no chemical modification occurred in the polymer. Thus, the relaxation times in the laboratory frame $T_{1}(\mathrm{H})$, in the rotating frame $T_{1 \rho}(\mathrm{H})$, and $T_{1 \rho}(\mathrm{C})$ and the cross-polarization time $\mathrm{T}_{\mathrm{CH}}$ were determined through solid-state NMR measurements in order to evaluate the dynamic modifications occurring in the polymeric chain of the PC matrix after composite formation. The $T_{1}(\mathrm{H}), T_{1 \rho}(\mathrm{H}), T_{1 \rho}(\mathrm{C})$ and $T_{\mathrm{CH}}$ values obtained from each peak in the ${ }^{13} \mathrm{C}$ spectra of all the samples are reported in Table 1.

The presence of the filler in the PC matrix did not significantly affect the $T_{1}(\mathrm{H})$. This indicates that the spin diffusion phenomenon averages the dynamic behavior of the polymer and that the composites are dynamically homogeneous in a range from tens to hundreds of nanometers. On the contrary, the $T_{1 \rho}(\mathrm{H}), T_{1 \rho}(\mathrm{C})$ and $T_{\mathrm{CH}}$ values are affected by the presence of silica. In the PC-silica composites loaded with $2 \%$ the $T_{1 \rho}(\mathrm{H})$ values are homogenous and similar to those of pure PC, but for the PC-silica composites loaded with $5 \%$ the $T_{1} \rho(\mathrm{H})$ values are inhomogeneous indicating a presence of inhomogeneity in the composite. This is not a surprise considering the presence of particle aggregates and it is in agreement with the observed thermal behavior.

For each sample, the $T_{1}(\mathrm{C})$ values of the carbonyl and substituted aromatic carbons are lower than those for the protonated aromatic, methyl and quaternary carbons. This finding suggests that the fast rotational motions of the methyl group and of the phenylene rings around the $1-4$ axis modulate the ${ }^{1} \mathrm{H}-{ }^{13} \mathrm{C}$ dipolar couplings thus providing the major contribution to the $T_{1} \rho$ relaxation. In particular, in the PC-silica composites loaded with $2 \%$ silica the $T_{1} \rho(\mathrm{C})$ values for the peaks at 149 and $42 \mathrm{ppm}$ are unchanged, but increased for the peaks resonating at 127.5, 120 and $31 \mathrm{ppm}$ with respect to that of the pure PC matrix. This is evidence that the small quantity of silica slows down only the rotational motion of the phenylene rings. On the other hand, in the PC-silica composites loaded with $5 \%$ silica an increase in the $T_{1}(\mathrm{C})$ values is also observed for the peaks at 149 and $42 \mathrm{ppm}$. This implies that the main chain motions and in particular those of the carbonyl carbon are 
Table 1

$T_{1}(\mathrm{H}), T_{1 \rho}(\mathrm{H}), T_{1 \rho}(\mathrm{C})$ and $T_{\mathrm{CH}}$ values for all the carbons in the ${ }^{13} \mathrm{C}$ spectra of PC and the $\mathrm{PC}-\mathrm{SiO}_{2}$ nanocomposites having 2 and 5 wt.\% of filler.

\begin{tabular}{|c|c|c|c|c|c|c|c|c|c|c|c|c|c|}
\hline \multirow[t]{2}{*}{ Carbon } & \multirow[t]{2}{*}{ ppm } & \multicolumn{3}{|l|}{$T_{1}(\mathrm{H})(\mathrm{s})$} & \multicolumn{3}{|c|}{$\underline{T_{1 \rho}(\mathrm{H})(\mathrm{ms})}$} & \multicolumn{3}{|c|}{$T_{1 \rho}(\mathrm{C})(\mathrm{ms})$} & \multicolumn{3}{|l|}{$\mathrm{T}_{\mathrm{CH}}(\mathrm{ms})$} \\
\hline & & PC & $\begin{array}{l}\mathrm{PC}-\mathrm{SiO}_{2} \\
(2 \%)\end{array}$ & $\begin{array}{l}\mathrm{PC}-\mathrm{SiO}_{2} \\
(5 \%)\end{array}$ & PC & $\begin{array}{l}\mathrm{PC}-\mathrm{SiO}_{2} \\
(2 \%)\end{array}$ & $\begin{array}{l}\mathrm{PC}-\mathrm{SiO}_{2} \\
(5 \%)\end{array}$ & PC & $\begin{array}{l}\mathrm{PC}-\mathrm{SiO}_{2} \\
(2 \%)\end{array}$ & $\begin{array}{l}\mathrm{PC}-\mathrm{SiO}_{2} \\
(5 \%)\end{array}$ & PC & $\begin{array}{l}\mathrm{PC}-\mathrm{SiO}_{2} \\
(2 \%)\end{array}$ & $\begin{array}{l}\mathrm{PC}-\mathrm{SiO}_{2} \\
(5 \%)\end{array}$ \\
\hline 1 & 149 & $0.39 \pm 0.02$ & $0.40 \pm 0.02$ & $0.41 \pm 0.03$ & $4.9 \pm 0.2$ & $5.9 \pm 0.2$ & $5.0 \pm 0.2$ & $41 \pm 0.2$ & $41.1 \pm 0.8$ & $53.4 \pm 0.2$ & $1328 \pm 127$ & $1009 \pm 53$ & $998 \pm 50$ \\
\hline 2 & 127.5 & $0.41 \pm 0.03$ & $0.41 \pm 0.02$ & $0.40 \pm 0.05$ & $5.4 \pm 0.2$ & $5.8 \pm 0.3$ & $6.3 \pm 0.3$ & $10.9 \pm 0.1$ & $16.0 \pm 0.3$ & $11.5 \pm 0.1$ & $117 \pm 28$ & $127 \pm 21$ & $142 \pm 14$ \\
\hline 3 & 120 & $0.39 \pm 0.01$ & $0.41 \pm 0.03$ & $0.39 \pm 0.01$ & $5.2 \pm 0.2$ & $5.0 \pm 0.3$ & $4.8 \pm 0.2$ & $10.2 \pm 0.2$ & $20.3 \pm 0.8$ & $15.8 \pm 0.4$ & $64 \pm 12$ & $151 \pm 21$ & $128 \pm 17$ \\
\hline 4 & 42 & $0.40 \pm 0.01$ & $0.38 \pm 0.03$ & $0.38 \pm 0.01$ & $4.8 \pm 0.2$ & $5.4 \pm 0.2$ & $6.2 \pm 0.3$ & $18 \pm 0.2$ & $18.3 \pm 0.4$ & $23.5 \pm 0.7$ & $1059 \pm 97$ & $744 \pm 51$ & $737 \pm 48$ \\
\hline 5 & 31 & $0.42 \pm 0.01$ & $0.38 \pm 0.03$ & $0.40 \pm 0.03$ & $4.9 \pm 0.3$ & $5.1 \pm 0.3$ & $5.3 \pm 0.3$ & $19.2 \pm 0.1$ & $23.5 \pm 0.3$ & $22.3 \pm 0.2$ & $275 \pm 20$ & $207 \pm 14$ & $231 \pm 17$ \\
\hline
\end{tabular}

hindered by the presence of silica. In this case the rotational and vibrational motions of the phenylene rings are slightly slowed. These observations are due to the intermolecular interactions involving the carbonyl groups of different polymeric chains which do not affect the intramolecular rotational motions. In addition, an increase in the dipolar coupling $\mathrm{T}_{\mathrm{CH}}$ for the carbonyl carbons, the quaternary and the methyl carbons is observed in the PC-silica nanocomposites, while an opposite trend is observed for the protonated aromatic carbons. $\mathrm{T}_{\mathrm{CH}}$ values are related to the rate at which the magnetization transfer from protons to carbons takes place. This behavior thus corroborates the hypothesis of specific intermolecular interactions caused by the silica in the composite, and may be accountable for the differences in thermal degradation and thermomechanical behavior observed between the different samples.

\section{Conclusions}

PC-silica nanocomposites, prepared by melt compounding, were systematically investigated as a function of silica quantity from 1 to $5 \mathrm{wt}$.\%. The silica nanoparticles, organized in clusters uniformly dispersed into the amorphous polymer. The polymer chain immobilization, increasing with the silica amount, is due to intermolecular interactions between silica and the polymer in the composite which do not involve the protonated aromatic carbons. The composites show the same degradation mechanism as pure PC. The thermal stability and the activation energy of the degradation process also depend on the amount of silica. In fact, the nanocomposites with silica loading up to $2 \mathrm{wt}$.\% have a higher thermal stability and show different degradation kinetics than the nanocomposites with 5 wt.\% silica loading.

\section{Acknowledgements}

The National Research Foundation in South Africa and the University of the Free State are acknowledged for financial support of the research. TEM and NMR experimental data were provided by Centro Grandi Apparecchiature - UniNetLab - Universitá di Palermo funded by P.O.R. Sicilia 2000-2006, Misura 3.15 Azione C Quota Regionale.

\section{References}

[1] Lagashetty A, Vijayanand H, Basavaraja S, Bedre MD, Venkataraman A Preparation, characteristics, and thermal studies of $\gamma-\mathrm{Fe}_{2} \mathrm{O}_{3}$ and $\mathrm{CuO}$ dispersed polycarbonate nanocomposites. J Therm Anal Calorim 2010;99:577-81. doi:http://dx.doi.org/10.1007/s10973-009-0475-8.

[2] Carrion FJ, Sanes J, Bermudez MD. Influence of $\mathrm{ZnO}$ nanoparticle filler on the properties and wear resistance of polycarbonate. Wear 2007;262:1504-10. doi:http://dx.doi.org/10.1016/j.wear.2007.01.016

[3] Carrion FJ, Sanes J, Bermudez MD. Effect of ionic liquid on the structure and tribological properties of polycarbonate-zinc oxide nanodispersion. Mater Lett 2007;61:4531-5. doi:http://dx.doi.org/10.1016/j.matlet.2007.02.044.

[4] Bermúdez MD, Brostow W, Carrión-Vilches FJ, Sanes J. Scratch resistance of polycarbonate containing $\mathrm{ZnO}$ nanoparticles: effect of sliding direction. J Nanosci Nanotechnol 2010;10:6683-9. doi:http://dx.doi.org/10.1166/ jnn.2010.251.
[5] Imai Y, Terahara A, Hakuta Y, Matsui K, Hayashi H, Ueno N. Transparent poly(bisphenol A carbonate)-based nanocomposites with high refractive index nanoparticles. Eur Polymer J 2009;45:630-8. doi:http://dx.doi.org/10.1016/ J.europolyj.2008.12.013.

[6] Xu K, Zhou S, Wu L. Effect of highly dispersible zirconia nanoparticles on the properties of UV-curable poly(urethane-acrylate) coatings. J Mater Sci 2009;44:1613-21. doi:http://dx.doi.org/10.1007/s10853-008-3231-8.

[7] Chau JLH, Hsu SLC, Chen YM, Yang CC, Hsu PCF. A simple route towards polycarbonate-silica nanocomposites. Adv Powder Technol 2010;21:341-3. doi:http://dx.doi.org/10.1016/j.apt.2010.02.005

[8] Christman A, Lenny P, Quantin JC, Caro-Bretelle AS, Cuesta JML. Mechanical behavior at large strain of polycarbonate nanocomposites during uniaxial tensile test. J Eur Ceram Soc 2011;52:4033-44. doi:10.106/j.polymer.2011.06. 056.

[9] Tan CS, Kuo TW. Synthesis of polycarbonate-silica nanocomposites from copolymerization of $\mathrm{CO}_{2}$ with allyl glycidyl ether, cyclohexene oxide, and solgel. J Appl Polym Sci 2005;98:750-7. doi:http://dx.doi.org/10.1002/app.22126.

[10] Suzuki N, Yamauchi Y. Fabrication of mesostructured silica and titania rods on substrates by using polycarbonate membranes. J Nanomater 2010:1-4. doi:http://dx.doi.org/10.1155/2010/38204.

[11] Luyt AS, Messori M, Fabbri P, Mofokeng JP, Taurion R, Zanasi T, et al. Polycarbonate reinforced with silica nanoparticles. Polym Bull 2011;66:991-1004. doi:http://dx.doi.org/10.1007/s00289-010-0408-5.

[12] Poręba R, Špírková M, Hrdlička Z. Mechanical and thermochemical properties of polycarbonate-based polyurethane-silica nanocomposites. Process Appl Ceram 2011;5:155-9. doi:10.10Sl/jp4:20030687.

[13] Saladino ML, Motaung TE, Luyt AS, Spinella A, Nasillo G, Caponetti E. The effect of silica nanoparticles on the morphology, mechanical properties and thermal degradation kinetics of PMMA. Polym Degrad Stab 2012;97:452-9. doi:10.1016/j.polymdegradstab.2011.11.006.

[14] Hartmann SR, Hahn EL. Nuclear double resonance in the rotating frame. Phys Rev 1962;128:2042-53.

[15] Lau C, Mi Y. A study of blending and complexation of poly(acrylic acid)/ poly(vinyl pyrrolidone). Polymer 2002;43:823-9. doi:http://dx.doi.org/ 10.1016/S0032-3861(01)00641-3.

[16] Alamo RG, Blanco JA, Carrilero I, Fu R. Measurement of ${ }^{13} \mathrm{C}$ spin-lattice relaxation time of the non-crystalline regions of semicrystalline polymers by a CP-MAS-based method. Polymer 2002;43:1857-65. doi:http://dx.doi.org/ 10.1016/S0032-3861(01)00761-3.

[17] Conte P, Spaccini R, Piccolo A. State of the art of CPMAS ${ }^{13} \mathrm{C}-\mathrm{NMR}$ spectroscopy applied to natural organic matter. Prog Nucl Magn Reson Spectrosc 2004;44:215-23. doi:http://dx.doi.org/10.1016/j.pnmrs.2004.02.002.

[18] Holland BJ, Hay JN. The value and limitations of non-isothermal kinetics in the study of polymer degradation. Thermochim Acta 2002;388:253-73. doi:http:// dx doi.org/10.1016/S0040-6031(02)00034-5.

[19] Gao Z, Kaneko T, Hou D, Nakada M. Kinetics of thermal degradation of poly (methyl methacrylate) studied with the assistance of the fractionation conversion at the maximum reaction rate. Polym Degrad Stab 2004;84:399-403. doi:http://dx.doi.org/10.1016/j.polymdegradstab.2003.11. 015.

[20] Vyazovkin S. A unified approach to kinetic processing of nonisothermal data. Int J Chem Kinet 1996;28:95-101. doi:10.1002/(sici)1097-4601(1996) 28:2<95::aid-kin4>3.0.co;2-g

[21] Motaung TE, Luyt AS, Bondioli F, Messori M, Saladino ML, Spinella A, et al. PMMA-titania nanocomposites: Properties and thermal degradation behaviour. Polym Degrad Stab 2012;97:1325-33. doi:http://dx.doi.org/ 10.1016/j.polymdegradstab.2012.05.022.

[22] Motaung, TE, Luyt AS, Saladino, ML, Chillura Martino DF, Caponetti E. Morphology, mechanical properties and thermal degradation kinetics of PMMA-zirconia composites prepared by melt compounding. Express Polym Lett 2012;6:871-81. doi: http://dx.doi.org./10.3144/expresspolymlett.2012. 93.

[23] Dong Q, Gao C, Ding Y, Wang F, Wen B, Zhang S, et al. A polycarbonate/ magnesium oxide nanocomposite with high flame retardancy. J Appl Polym Sci 2011:123:1085-93. doi:http://dx.doi.org/10.1002/app.34574.

[24] Eijkelenboom APAM, Maas WEJR, Veeman WS, Buning GHW, Vankan JMJ. Triple-resonance fluorine-19, proton, and carbon-13 CP-MAS NMR study of the influence of PMMA tacticity on the miscibility in PMMA/poly(vinylidene fluoride) (PVF2) blends. Macromolecules 1992;25:4511-8. 